\title{
Differential diagnoses and treatment of lipedema
}

\author{
Maria Wiedner, Donia Aghajanzadeh, Dirk F. Richter \\ Department for Plastic and Aesthetic Surgery, Dreifaltigkeitskrankenhaus Wesseling, Wesseling 50389, Germany.
}

Correspondence to: Dr. Maria Wiedner, Department for Plastic and Aesthetic Surgery, Dreifaltigkeitskrankenhaus Wesseling, Bonner Strasse 84, Wesseling 50389, Germany. E-mail maria@wiedner-plastic.com

How to cite this article: Wiedner M, Aghajanzadeh D, Richter DF. Differential diagnoses and treatment of lipedema. Plast Aesthet Res 2020;7:10. http://dx.doi.org/10.20517/2347-9264.2019.51

Received: 3 Nov 2019 First Decision: 29 Nov 2019 Revised: 15 Jan 2020 Accepted: 3 Feb 2020 Published: 6 Mar 2020

Science Editor: Xiao Long Copy Editor: Jing-Wen Zhang Production Editor: Jing Yu

\begin{abstract}
Lipedema is a frequently unrecognized and misdiagnosed disorder of the fatty tissue of extremities and hips, which affects almost purely women. The beginning of the disease usually occurs with hormonal changes, such as puberty, pregnancy, or menopause. Women suffer from pain, easy bruising, and disfigurement, which may lead to early immobility and social stress. Accurate diagnosis and treatment are essential. The differentiation between obesity and lipedema is difficult, as these two different entities often occur together. Other differential diagnoses are lymphedema, benign lipohypertrophy, and Dercum's disease. A therapy targeting the underlying cause of lipedema is not available because the exact etiology of the disorder is not clarified yet. Decongestive physical therapy is the basic conservative treatment, which is usually necessary lifelong. However, liposuction has led to a paradigm shift in the treatment of lipedema. The purposes of this article are to describe the symptoms and treatment options of the still fairly unknown disease Lipedema and to show the distinctions to its differential diagnoses.
\end{abstract}

Keywords: Lipedema, lymphedema, obesity, symmetrical limb enlargement, adipositas dolorosa

\section{INTRODUCTION}

Lipedema is a painful disease of the subcutaneous tissue, which was first named in 1940 by Allen and Hines. They described a syndrome characterized by "large legs due to the subcutaneous deposition of fat in the buttocks and lower extremities and the accumulation of fluid in the legs" ${ }^{\text {"[1] }}$. It is a painful, possibly chronically progressive disorder of adipose tissue that is characterized by symmetrical swelling of the lower and/or upper limbs. Patients typically complain about increased pressure sensitivity and easy bruising and may also experience ankle edema. In advanced stages, lymphedema may additionally occur, especially in those who are obese. 
Lipedema is possibly a common but underdiagnosed disorder, which is almost exclusively found in females, but, as there is no standardized diagnostic test, the exact prevalence is unknown. According to German studies, $8 \%-18 \%$ of patients referred to a lymphedema clinic suffer from lipedema ${ }^{[2-4]}$.

The pathogenesis is not fully understood yet. Lipedema often affects several female members of the same family, suggesting a genetic disorder ${ }^{[5]}$. A positive family history is common and ranges between $16 \%$ and $64 \%{ }^{[6]}$, but is likely higher due to under-diagnosis. Autosomal dominant inheritance with incomplete penetrance and sex limitation is the most likely mode of inheritance ${ }^{[5,7]}$. Since the disease usually manifests or is aggravated around hormonal changes (puberty, pregnancy, and menopause), lipedema is assumed to be an estrogen-regulated polygenetic disease. It is associated with vasculo- and lymphangiopathy ${ }^{[8]}$. There are numerous theories on pathogenesis. On the one hand, an altered estrogen-receptor pattern and responsiveness is assumed to exist centrally. On the other hand, pathologic estrogen-receptor patterns (alpha/beta) in the adipose tissue lead to increased lipogenesis and decreased lipolysis in the affected $\operatorname{areas}^{[8]}$.

Histologically, the fat deposition is a result of hyperplasia and hypertrophy of fat cells in the subcutaneous adipose tissue ${ }^{[8]}$. Additional mechanisms were demonstrated to play a role in the pathogenesis of lipedema including increased vascular permeability and damage (microangiopathy), excessive lipid peroxidation, and disturbances in adipocyte metabolism and cytokine production ${ }^{[9,10]}$. Inflammation of the peripheral nerves and sympathetic innervation abnormalities of the subcutaneous adipose tissue may be responsible for neuropathy ${ }^{[8]}$. One recent investigation on differences between adipose stem cells from lipedema and nonlipedema donors indicated that in vitro adipogenesis of lipedema adipose stem cells is severely hampered in comparison to non-lipedema adipose stem cells and that lipedema adipose stem cells not only differ in their lipid storage capacity but also in their adipokine expression pattern ${ }^{[1]}$. The findings indicate that this might serve as a valuable marker for diagnosis of lipedema, probably from an early stage.

Due to lack of knowledge, lipedema used to be a frequently unrecognized and misdiagnosed disorder. For a long time, the disease was equated with obesity, although lipedema fat is more resistant to reduction by diet and exercise than non-lipedema fat. The condition should be clearly distinguished from other dysfunctions of fat distribution, mixed forms of obesity and lymphedema. In addition to the progressive physical symptoms and consequences (lymphatic, dermatologic, and orthopedic problems), psychosocial distress with comfort eating and depression frequently arise in lipedema patients.

The diagnosis of lipedema is usually based on medical history and clinical features ${ }^{[6]}$. One criterion is the onset of the disease in parallel with hormonal changes and occurrence mainly in women ${ }^{[1,12]}$. Lipedema typically presents with a disproportionate enlargement of the limbs in relation to the upper part of the body $^{[6,13]}$ [Figure 1]. Increase of adipose tissue of the limbs is symmetrical, without involvement of feet or hands. Fat deposits begin abruptly above the malleoli, which creates the "cuff sign" ${ }^{[6]}$ [Figure 2]. Other clinical criteria of lipedema comprise spontaneous or minimal trauma induced bruising, pain, and worsening during the day ${ }^{[5,14]}$.

The severity of lipedema can be classified into four clinical stages according to skin conditions and the sizes of the palpable and visible fat nodules ${ }^{[15,16]}$ [Figure 3]:

Stage 1: Flat skin with thickened subcutaneous tissue;

Stage 2: Increasing subcutaneous fat and walnut to apple-like indurations in the skin akin to a mattress;

Stage 3: Larger indurations and deforming skin-fat lobes, especially in the thighs and knee areas;

Stage 4: Development of additional lymphedema (lipolymphedema).

The development of lymphedema with lipedema (often known as lipolymphedema) can occur with any stage $^{[10]}$. After a mean of about ten years suffering from lipedema, the lymphatics likely become insufficient. 


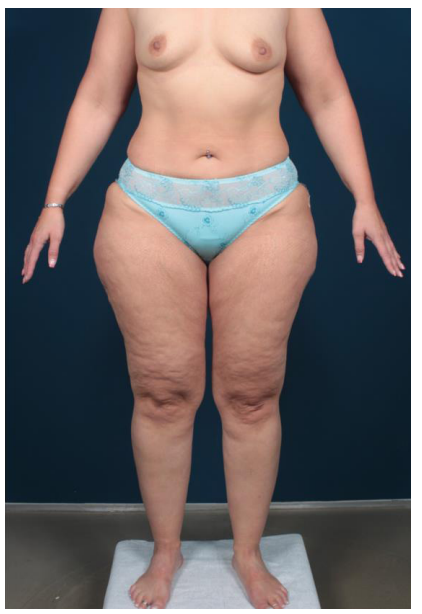

Figure 1. Disproportionate enlargement of the lower limbs in relation to the upper part of the body

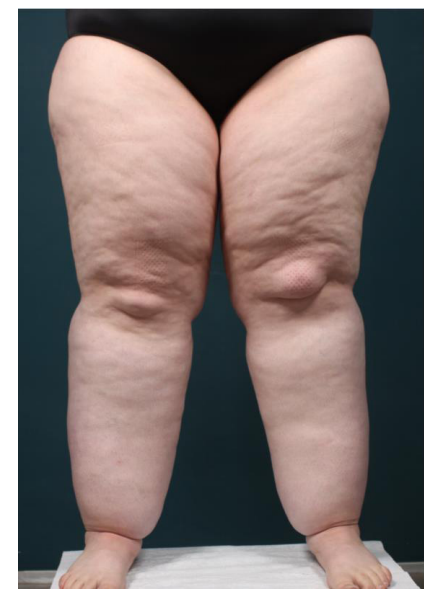

Figure 2. Typical cuff sign. The disproportionate fat accumulation in Stage 1-3 Lipedema patients stops proximal of the malleoli

In addition to the direct impairment of lymph vessels (fragility and compression by fat), a high volume insufficiency leads to increased edema.

In advanced stages, joint malformations are commonly seen due to the mass of soft tissue.

According to the pattern of fat distribution, one classification distinguishes five types of lipedema ${ }^{[17]}$ : Type I: Pelvis, buttocks, and hips (saddle bag phenomenon);

Type II: Buttocks to knees, with formation of folds of fat around the inner side of the knee;

Type III: Buttocks to ankles;

Type IV: Arms;

Type V: Lower leg.

There may be a mixture of lipedema types in one person. Only the arms may be affected in $3 \%$ of lipedema cases (Type IV $)^{[18]}$.

\section{DIFFERENTIAL DIAGNOSIS}

Lipedema is often misdiagnosed and differential diagnosis is sometimes challenging. The disease has to be clearly distinguished from other entities. 

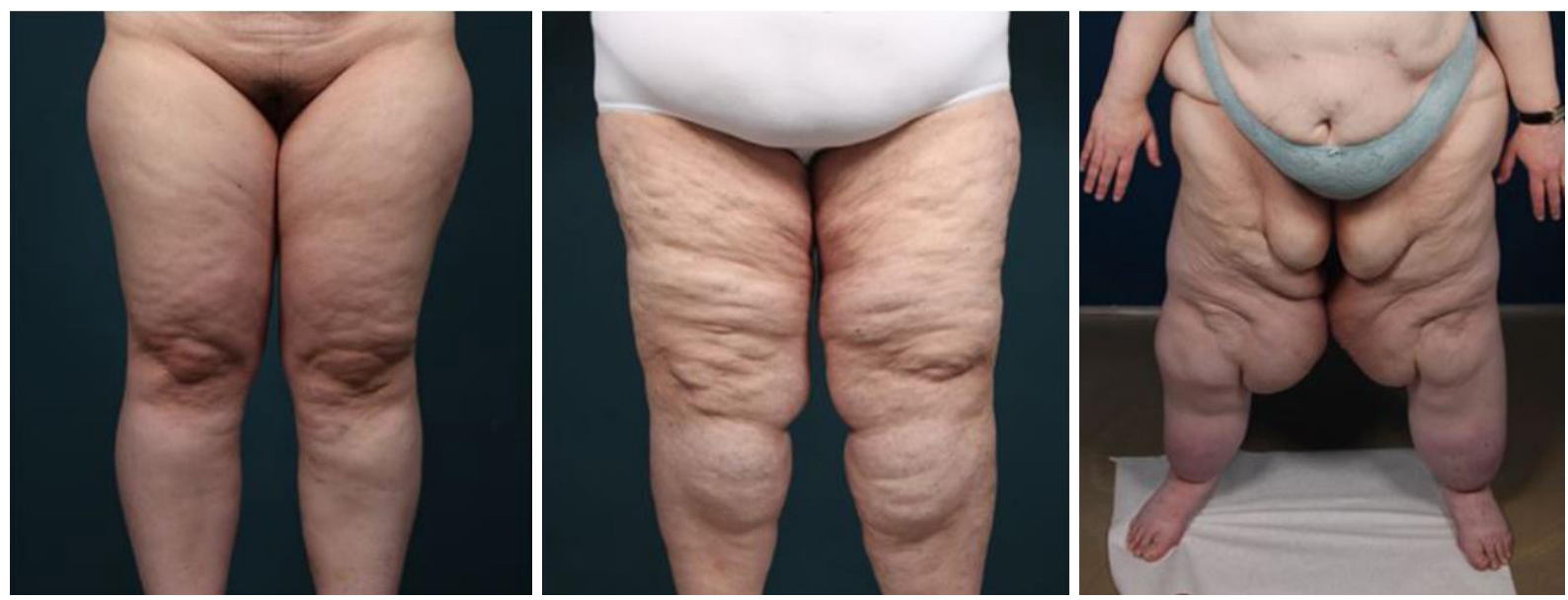

Figure 3. Different stages of lipedema according to the size of the fat nodules in the subcutaneous tissue: (left) Stage 1 shows a thickening of the subcutaneous tissue with small palpable nodules; (middle) Stage 2 already shows bigger fatty nodules up to walnut-size; and (right) Stage 3 is defined by overhanging skin-fat lobules, especially in the medial knee area or the development of severe column legs with cuff sign

One such is benign lipohypertrophy. Morphologically, lipohypertrophy may resemble lipedema. Women suffer from a constitutional disproportion of body shape with symmetrical hip- and thigh-obesity. The most common form of lipohypertrophy is the "riding breeches" obesity. The upper extremities are rarely affected. In contrast to lipedema, lipohypertrophy presents without pain, edema, or bruising ${ }^{[19]}$. It is thought that lipedema may develop from lipohypertrophy over time ${ }^{[20,21]}$. However, it is not entirely clear that these are truly separate conditions.

Another differential diagnosis of lipedema is primary lymphedema, which may also affect women around puberty. Concerning differences between lipedema and primary lymphedema, patients with lipedema present symmetrical swellings, whereas primary lymphedema is usually asymmetrical [Figure 4]. While lymphedema typically starts at the toes and subsequently reaches the thighs, swellings in lipedema patients usually affect the thighs first. One clinical differentiating factor is the Stemmer sign: lymphedema often presents a positive Stemmer sign, which describes the inability to pinch the skin over the proximal phalanx of the second toe, while Stemmer sign is negative in pure lipedema ${ }^{[22]}$ [Figure 5]. Another significant difference between lipedema and lymphedema is the presence of pain and frequent bruising in lipedema. However, a visible lymphedema can occur with any stage of lipedema ${ }^{[10]}$.

Phlebolymphedema is the result of chronic venous insufficiency. It may occur in men and women, either uni- or bilaterally. Discolorations of the skin, varicose veins, or ulcer formations are typical symptoms. In contrast to lipedema, ultrasound examination in phlebolymphedema shows pathological findings. However, women with lipedema may also have varicose veins and may develop phlebolymphedema as a result of these ${ }^{[20]}$.

Dercum's disease, also known as adipositas dolorosa, describes a condition characterized by generalized obesity and painful, fatty tumors (lipomata) in the adipose tissue, occurring almost exclusively in women. The tumors are found on the extremities, without involvement of the feet. It is said that it commonly develops around menopause. In contrast to lipedema, edema is not present. Muscular weakness and fatigue, emotional instability, depression, and alcohol abuse are potential features of the disease ${ }^{[23]}$. However, it is controversial whether Dercum's disease represents a separate entity or it is only a variant of lipedema. 


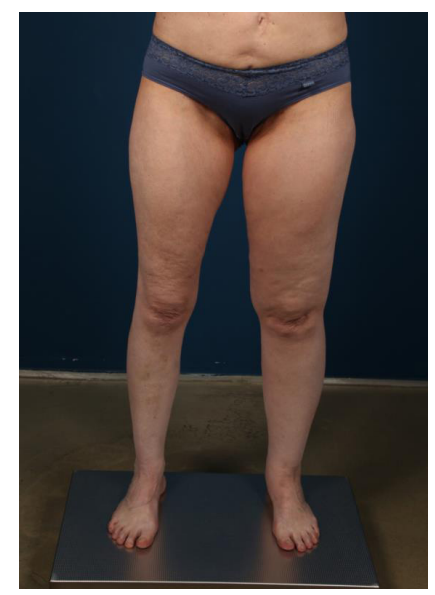

Figure 4. Asymmetrical limb swelling in a lymphedema patient with her left lower limb affected

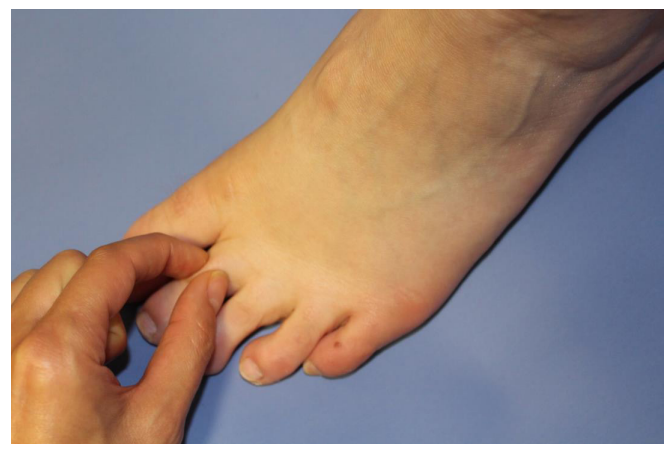

Figure 5. Stemmer sign. It is negative in Lipedema patients. Here you can lift the skin of the dorsum of the second toe, which is not possible in Lymphedema patients (positive Stemmer sign)

Madelung's Disease, also known as benign symmetrical lipomatosis and Launois-Bensaude disease, is a disorder of fat metabolism that results in an unusual accumulation of fat deposits around the neck (Type I), shoulder areas and upper arms (Type II), or pelvic areas (Type III). The condition is most common in men and almost always associated with alcohol abuse and liver damage ${ }^{[24]}$ [Figure 6].

Lipedema is frequently misdiagnosed as obesity. While obesity affects the whole body, lipedema usually affects the upper and/or lower limbs and does not involve the feet and hands. Patients with lipedema hardly respond to restricted diet ${ }^{[25]}$. Even after extreme weight loss, for example after bariatric surgery or in cancer cachexia, patients typically lose less fat in the areas affected by lipedema than in the nonaffected areas [Figure 7]. Lipedema and obesity share the hallmark of symmetrical fat increase ${ }^{[26]}$. However, differential diagnostic criteria include the different distribution of fat in obesity (which is typically more in the "central" pattern) and that the fat is not usually tender/painful. Weight loss by dieting and exercise in chronic lipedema patients can often be frustrating, because there is less fat reduction in the affected limbs than on the trunk. Furthermore, weight gain can result in excess fat deposition in the legs. Thus, in women with lipedema who cannot sustain weight loss, there is a risk of progression of the lipedema. This seems to be more likely in women who experience periods of weight loss followed by periods of weight gain. Management of any associated obesity is therefore crucial to the successful management of lipedema. Bariatric surgery may be a successful way of reducing weight and maintaining the achieved loss ${ }^{[27]}$.

A recent review highlights the utility of developing a genetic diagnostic test containing candidate genes for lipedema and causative genes of diseases that can be confused with lipedema, to help differentiate lipedema 

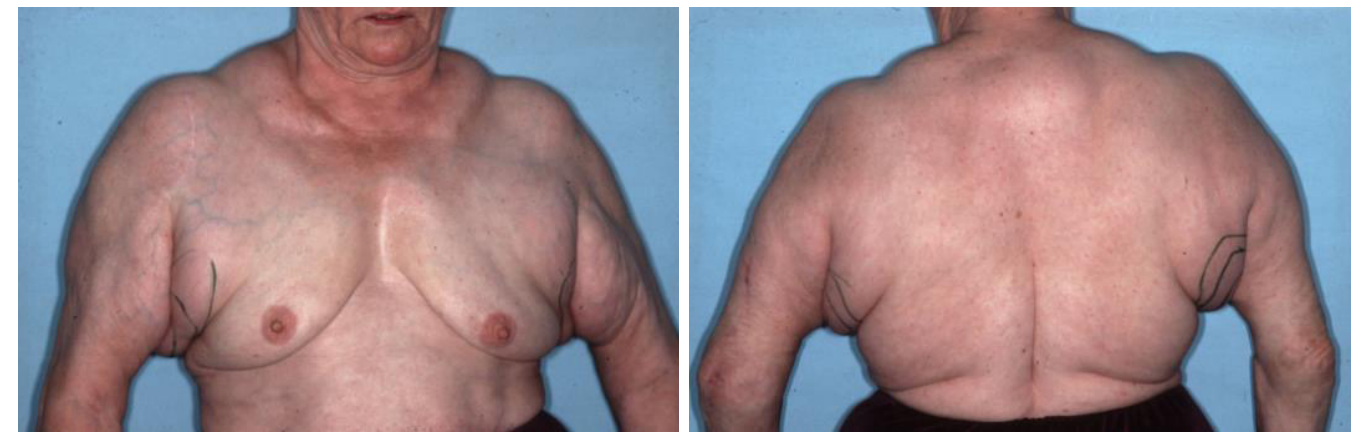

Figure 6. Madelungs disease Type II with fat accumulations in the neck, shoulders, and arms

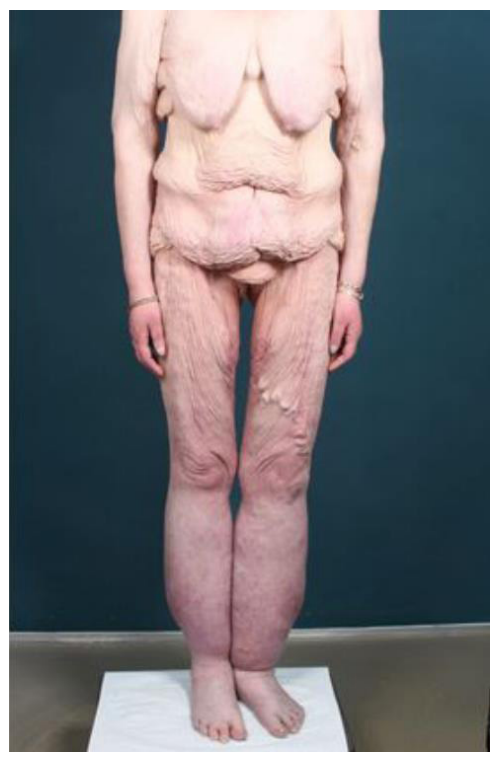

Figure 7. Patient after bariatric surgery and massive weight loss. She did not lose the lipedema fat in the affected lower legs

from other diagnoses ${ }^{[28]}$. The list of differential diagnoses criteria of lipedema modified from Schmeller in 2005 is shown in Table $1^{[29]}$.

\section{THERAPY}

A targeted therapy aimed at the cause of lipedema is not known because the exact etiology is still unexplained. Therapy has essentially two objectives: (1) resolve or improve symptoms (edema, pain, and disproportion); and (2) prevent disease progression and the development of complications (lymphatic, dermatologic, and orthopedic problems). A distinction is made between conservative therapy to decongest the subcutaneous tissue and surgical therapy such as liposuction to reduce adipose tissue. As discussed above, weight management is a key component of both objectives.

Conservative approaches include compression garment therapy or wrapping to reduce edema and manual lymphatic drainage (MLD) as part of an outpatient context or as part of a complex decongestive physiotherapy (CDP). CDP is a very time-consuming therapy, being performed twice a day for 45-60 min over a period of 3-4 weeks, mainly in lymphedema clinics in an inpatient context. A component of CDP is manual lymphatic drainage. MLD is a type of gentle skin massage which stimulates contraction of the lymph collectors and enhances protein resorption. In addition to improving lymphatic circulation, MLD 


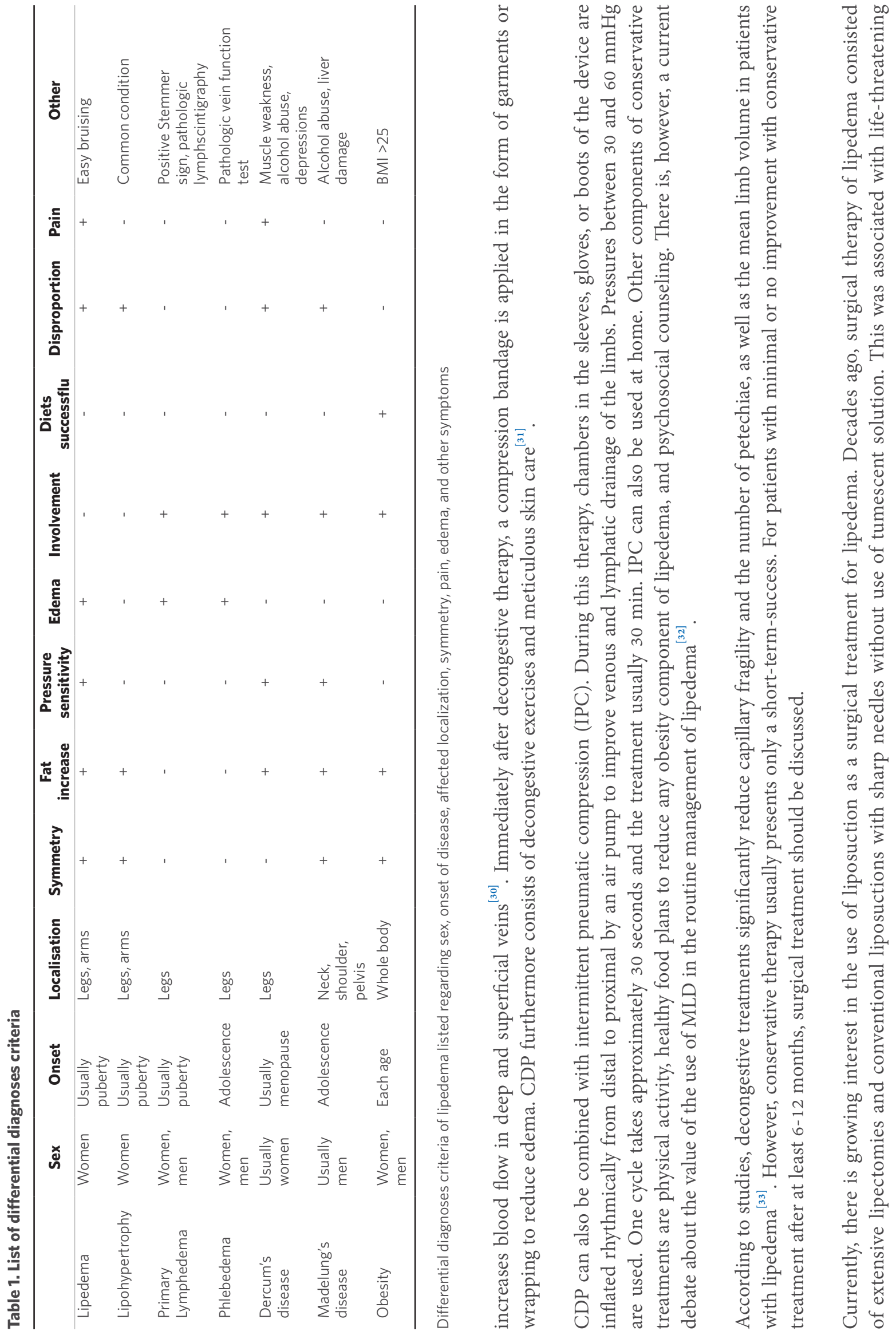



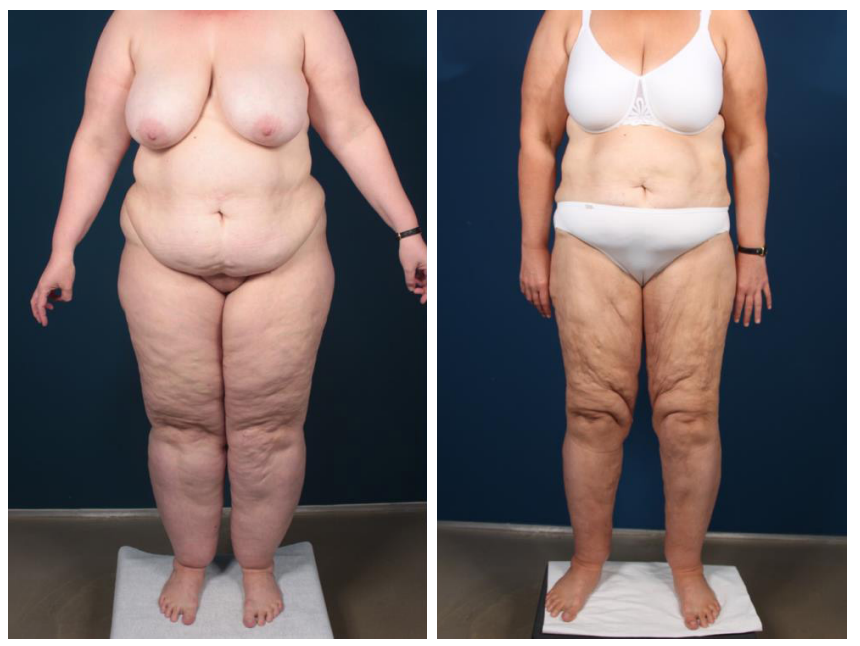

Figure 8. Lipedema Stage 3 patient before and after five sessions of liposuction in the lower legs

complications as well as persistent postoperative edema due to damage to the lymphatic vessels. As a result, conventional dry liposuction under general anesthesia was therefore contraindicated in lipedema patients $^{[34]}$.

Nowadays, the "wet", "super-wet", and "tumescent" techniques are used, which are less likely to damage the lymphatic system compared to the conventional "dry" technique. The use of microcannulas as well as new liposuction techniques such as power-assisted liposuction with vibrating cannulas or waterjet-assisted liposuction have been shown to further minimize tissue trauma and complication rates.

When performing liposuction in lipedema patients, the crisscross technique, which is commonly used in aesthetic surgery, is contraindicated because of the higher risk of harming lymph vessels with consecutive development of lymphedema. Therefore, it is of great importance to take the lymph vessel anatomy into account and move the cannula parallel to the lymph vessels in order to save them. This is why more incisions are usually needed to remove the fat from the affected area.

Since 2005, guidelines of the German Society of Phlebology recommend liposuction as an integrated part of therapy ${ }^{[35]}$. Tumescent liposuction has been demonstrated to reduce disproportions and pain permanently ${ }^{[36]}$, stop progression of the disease ${ }^{[35,36]}$, and improve quality of life ${ }^{[37-40]}$. In addition, surgical therapy may reduce the amount of necessary conservative therapy ${ }^{[38,40]}$. Weight management is an important requirement for maintaining the benefits of liposuction. There are reports that fat can re-accumulate in those who put on weight after liposuction.

Most patients undergoing liposuction for lipedema require several treatments over several months. According to the guidelines, more than 4-6 liters of fat per session should not be removed because the risk of cardiopulmonary complications increases with increasing blood and fluid loss. Electrolyte imbalances are particularly dangerous. Usually, a minimal interval of at least three months between the sessions is recommended. Figure 8 shows a 36-year-old patient after five sessions of liposuction.

In conclusion, Lipedema is a frequently unrecognized and misdiagnosed disorder. Clinicians should be aware of clinical signs and clearly distinguish the condition from other entities. Accurate diagnosis and treatment are essential because they determine the patient's prognosis. A targeted therapy for lipedema is not known because the exact etiology of the disorder is not clarified yet. Decongestive physical therapy is the basic conservative treatment, which is usually necessary lifelong. However, liposuction has led 
to a paradigm shift in the treatment of lipedema. While conservative therapy may reduce symptoms temporarily, liposuction is able to remove the pathologic adipose tissue, which may result in a sustainable symptom relief. Liposuction is an effective surgical method and should be individually considered for patients suffering from lipedema. Weight management is a key component of successful treatment whether conservative or surgical.

\section{DECLARATIONS}

\section{Authors' contributions}

Made substantial contributions to conception and design of the article: Wiedner M, Aghajanzadeh D, Richter DF

\section{Availability of data and materials}

Not applicable.

\section{Financial support and sponsorship}

None.

\section{Conflicts of interest}

All authors declared that there are no conflicts of interest.

\section{Ethical approval and consent to participate}

Not applicable.

\section{Consent for publication}

Written informed consent for publication of images was obtained from the patients shown on the images.

\section{Copyright}

(c) The Author(s) 2020.

\section{REFERENCES}

1. Allen EV, Hines EA. Lipedema of the legs: a syndrome characterised by fat legs and orthostatic edema. Proc Staff Meet Mayo Clin 1940;15:184-7.

2. Herpertz U. Krankheitsspektrum des lipödems an einer lymphologischen fachklinik- erscheinungsformen, mischbilder und behandlungsmöglichkeiten. Vasomed 1997;5:301-3.

3. Meier-Vollrath I, Schneider W, Schmeller W. Lipödem: Verbesserte Lebensqualität durch Therapiekombination. Deutsches Ärzteblatt 2005;15:A1061-7.

4. Lulay G. Lymphologische akutklinik- ein neues versorgungskonzept. Lymphol Forsch Praxis 2010;14:90-5.

5. Child AH, Gordon KD, Sharpe P, Brice G, Ostergaard P, et al. Lipedema: an inherited condition. Am J Med Genet A 2010;152A:970-6.

6. Langendoen SI, Habbema L, Nijsten TE, Neumann HAM. Lipoedema: from clinical presentation to therapy. A review of the literature. Br J Dermatol 2009;161:980-6.

7. Weissleder H, Schuchhardt C, et al. Lymphedema. Diagnosis and therapy. WVP. Wirtschafts- und Praxisverlag; 2007.

8. Szél E, Kemény L, Groma G, Szolnoky G. Pathophysiological dilemmas of lipedema. Med Hypotheses 2014;83:599-606.

9. Mayes JS, Watson GH. Direct effects of sex steroid hormones on adipose tissues and obesity. Obes Rev 2004;5:197-216.

10. Herbst K, Mirkovskaya L, Bharhagava A, Chava Y, Te CHT. Lipedema fat and signs and symptoms of illness, increase with advancing stage. Arch Med 2015;7:10.

11. Bauer AT, Lukowicz D, Lossagk K, Hopfner U, Kirsch M, et al. Adipose stem cells from lipedema and control adipose tissue respond differently to adipogenic stimulation in vitro. Plast Reconstr Surg 2019;144:623-32.

12. Brauer W, Cornely M, Faerber G, Lulay GR., Miller A, et al. Lipödem S1 Leitlinie. Available from: https://www.phlebology.de/aerzte/ wissen/leitlinien/ [Last accessed on 16 Feb 2020] (in German)

13. Van Geest AJ, Esten SCAM, Cambier J-PRA, Gielen EGJ, Kessels A, et al. Lymphatic disturbances in lipoedema. Phlebologie $2003 ; 32: 138-42$

14. Wold LE, Hines Jr EA, Allen EV. Lipedema of the legs: a syndrome characterized by fat legs and edema. Ann Intern Med 1951;34:1243- 
50.

15. Fife CE, Maus EA, Carter MJ. Lipedema: a frequently misdiagnosed and misunderstood fatty deposition syndrome. Adv Skin Wound Care 2010;23:81-92.

16. Meyer-Vollrath I, Schmeller W. Lipödem - aktueller stand, neue Perspektiven. J Dtsch Dermatol Ges 2004;2:181-6.

17. Schneider W, Meier-Vollrath I. Das lipodem: neue möglichkeiten der therapie. Schweiz Med Forum 2007;7:150-5.

18. Herpertz U. Lipedema. Z Lymphol 1995;19:1-11. (in German)

19. Müssig K, Gallwitz B. Lipohypertrophie. Dtsch Med Wochenschr 2006;131:1807-8. (in German)

20. Herpertz U. Ödeme und Lymphdrainage. Diagnose und Therapie von Ödemkrankheiten. 2nd ed. Stuttgart, New York: Schattauer; 2004. pp. 168-18122.

21. Marsch WC. Ist das Lipödem ein lympho-logisches krankheitsbild? J Lymphologie 2001;1:22-4.

22. Stemmer R. Ein klinisches zeichen für früh- und differentialdiagnostik des lymphödems. Vasa 1976;3:261-2.

23. DeFranzo AJ, Hall JH, Herring SM. Adiposis dolorosa (Dercum's disease): liposuction is an effective form of treatment. Plast Reconstr Surg 1990;85:289-92.

24. Ruzicka T, Vieluf D, Landthaler M, Braun-Falco O. Benign symmetric lipomatosis Lau-nois-Bensaude. Report of ten cases and reviewof the literature. J Am Acad Dermatol 1987;17:663-74.

25. Schmeller W, Meyer-Vollrath I. Erfolgreiche operative therapie des lipödems mittels liposuktion. Phlebologie 2004;33:23-9.

26. Bertsch T, Erbacher G. Lipoedema - myths and facts Part 3. Phlebologie 2018;47:188-97.

27. Bertsch T, Erbacher G. Torio-Padron N. Lipoedema - myths and facts Part 4. Phlebologie 2019;48:47-56.

28. Paolacci S, Precone V, Acquaviva F, Chiurazzi P, Fulcheri E, et al. Genetics of lipedema: new perspectives on genetic research and molecular diagnoses. Eur Rev Med Pharmacol Sci 2019;23:5581-94.

29. Schmeller W, Meyer-Vollrath I. Lipödem: ein Update. LymphForsch 2005;9:10-20.

30. Crisóstomo RSS, Candeias MS, Armada-da-Silva PAS. Venous flow during manual lymphatic drainage applied to different regions of the lower extremity in people with and without chronic venous insufficiency: a cross-sectional study. Physiotherapy 2017;103:81-9.

31. International Society of Lymphology. The diagnosis and treatment of peripheral lymphedema. Consensus document of the international society of lymphology. Lymphology 2003;36:84-91.

32. Bertsch T, Erbacher G. Lipoedema - myths and facts Part 2. Phlebologie 2018;47:120-6.

33. Szolnoky G, Nagy N, Kovács RK, Dósa-Rácz E, Szabó A, et al. Complex decongestive physiotherapy decreases capillary fragility in lipedema. Lymphology 2008;41:161-6.

34. Stiefelhagen P. No lymphedema, no obesity. How can lipedema be treated? MMW Fortschr Med 2001;143:15.

35. Wienert V, Földi E, Schmeller W, Rabe E. Leitlinie: Lipödem der Beine. Phlebologie 2005;34:38-40.

36. Rapprich S, Loehnert M, Hagedorn M. Therapy of lipoedema syndrome by liposuction under tumescent local anaesthesia. Ann Dermatol Venerol 2002;129:1S-711.

37. Cornely ME. Fatter through lipids or water. Lipohyperplasia dolorosa versus lymphedema. Hautarzt 2010;61:873-9. (in German)

38. Rapprich S, Dingler A, Podda M. Liposuktion ist eine wirksame therapie beim lipödem - ergebnisse einer untersuchung mit 25 patientinnen. J Deutsch Dermatol Ges 2011;9:33-40.

39. Schmeller W, Tronnier M, Kaiserling E. Lymphgefäßschädigung durch liposuktion? Eine immunhistologische untersuchung. LymphForsch 2006;10:80-4.

40. Schmeller W, Huepp M, Meier-Vollrath I. Tumescent liposuction in lipoedema yields good long-term results. Br J Dermatol 2011;166:161-8. 